\title{
Awareness of E-Cigarettes among Student in Malaysian Public University
}

\author{
Rafidah Abd Razak ${ }^{1}$, Nor Hazlyna, $\mathbf{H}^{2}$, Azrul Edzwan Shahril ${ }^{3}$, Azreen Natasha Azman ${ }^{4}$ \\ N.Muhd Naim Zainudin 5 \\ 1,2,3,4,5 School of Computing, Universiti Utara Malaysia (UUM) Sintok, Kedah Darul Aman, Malaysia \\ hazlyna@uum.edu.my²
}

Article History: Received: 10 November 2020; Revised: 12 January 2021; Accepted: 27January 2021; Published online: 05April 2021

\begin{abstract}
Purpose: The intention of this research is to develop understanding of e-cigarette awareness towards students in university. Method: The data collection method used in this study is online survey using Google form applications via social media platforms. The respondents consist of 304 students from Malaysian public university located in north Malaysia. This survey consists of 14 questions including the demographic question. Result: Most of the respondents $(\mathrm{n}=304)$ were aware of the impact of e-cigarettes and 124 (40.79 percent) had used an e-cigarette previously. E-cigarette awareness is also high among female students compared to male students.Conclusion: Importantly, attention needs to be paid to the use of ecigarettes. Besides that, government law enforcement needs to be restructured to monitor the e-cigarette product from direct to adult access. Institutions also need to play a role in exposing students to awareness of e-cigarettes by increasing awareness programs. Overall, this study suggests a further research on this area to be conducted in a large scope of population in Malaysia and demographic locations.
\end{abstract}

Keywords: Awareness, e-cigarette, smoking, student, university, education, tobacco

\section{Introduction}

There are many studies on smoking that cause multiple severe illnesses (Cheah et al., 2019). The World Health Organization (World Health Organization, 2018) stated that there are more than eight billion smokers around the world who were killed by smoking. In addition, the statistics also stated that 80 percent of cigarette users were from low income groups that tend to buy cigarettes rather than spending on daily needs (World Health Organization, 2018).

An e-cigarette is a device operated by using a battery that produces steam results for breathing in which is the mixture containing nicotine (Tomashefski et al., 2016). The objective is to establish a feeling of inhalation of tobacco smoke that is in a variety of shapes, for example USB drives and pens (Brazier Y, 2020). Suppliers advertise e-cigarettes as devices for reducing or who are trying to stop smoking, but are labelled by the Food and Drug Administration (FDA) as tobacco products (Brazier Y, 2020).

The objectives are equivalent to a normal cigarette, vape that has no burning or smoke produced, but only vapor. This system is distributed using batteries with nicotine and glycerine (Alanazi et al., 2016). The specifications of the e-cigarettes are made based on the manufacturer of the device. In addition, there are certain designs and dimensions, flavours, and techniques of handling. E-cigarette and smoking are not only harmful to the smokers, but also to the people around them, hence causing problemsdepending on the body system's implications (Dresden, 2019). In other words, smoking can raise the risk of a chronic illness such as lung diseases (Edwards, 2019).

Therefore, one must realize that smoking e-cigarettes is no different with the harmful effects of normal cigarettes because they contain glycerine, preservatives ingredients and some other addictive substances (Daniluk et al., 2020). This statement created an avenue to conduct a study on awareness of e-cigarettes among students in this university. This research has provided the result that we need to analyse the awareness among student about the implication of smoking e-cigarettes

Adib et al. stated in their study on the awareness of e-cigarettes that the most of respondents who are also university students had never tried e-cigarettes (Adib et al., 2018). This shows that most university students nowadays are aware of the usage of e-cigarettes. Furthermore, to make it more robust, this study is also similar to (Lotrean et al., 2015) which mentions that most of their students have also never tried e-cigarettes. Hence, it is related to the objective of this study on the awareness of e-cigarettes among students in the university.

The existence of e-cigarettes has become trending among smokers as stated in (Wong et al., 2016) conducted in 2016, whereby, out of six institutions, 1,302 candidates were chosen randomly. Thirty-six percent of the respondents were from Selangor, Kuala Lumpur and 39.9 percent of e-cigarette users were students (Wong et al., 
2016). Therefore, this factor topic relates to this study on the awareness of e-cigarettes among students in the university. This study aims to identify the awareness of the students in university on the impact of smoking ecigarettes, the effects of e-cigarettes towards health and the factor that causes the use of e-cigarettes.

\section{Method}

\subsection{Data Gathering Technique}

Research instruments used in this study are based on online surveys using Google Form Applications. Yun as cited in (Adib et al., 2018) reported that polls allow the researcher to reach out to many participants in a short period by minimizing geographic ranges. In addition, this survey is carried out via social media channels, namely Telegram, WhatsApp, and other social platforms by providing a link https:/bit.ly/3ejxQL1. Data collection was conducted within two months from 30th April 2020 until 4th June 2020. The respondents are students with different levels of studies starting from foundation, undergraduate and postgraduates. The list of respondents were randomly selected based on social media blast.

\subsection{Study Respondent and Background}

The respondents of this study included 304 students from one of the publicuniversity in northMalaysia by completing a survey aimed at improving the understanding of the use of e-cigarettes among students. The survey participants were students from the age of 18 years and above. The participants in this study were selected randomly and remain anonymous about their identity.

\subsection{Study Survey}

The study used the questionnaire in the article Student Details on the use of e cigarettes in Malaysia (Adib et al., 2018) and in the report on E-cigarette Use and Views of Urban Public school students in North Carolina (Alanazi et al., 2016) as references. This questionnaire contains 14 questions, along with demographic questions and the survey instrument was approved by an Institutional Review Board (IRB) at the University of East Carolina, Greenville, North Carolina, covering multiple-choice answers and closed questions of 'yes' or 'no' answers. The questionnaire was adopted from the article in (Alanazi et al., 2016) and some questions from the article in (Adib et al., 2018) were added to make sure the data collected is able to answer the objectives of the study.

\subsection{Data Exploration}

The information obtained was examined and tested to verify the relevance of the research approach. This data was explored by pre-processing the original data to remove the outlier that will make the result bias. Furthermore, the data were split based on gender in this study which identified the dominance level of awareness between male and female. The data were analyzed by using the Orange software which makes it easier for researchers to extract the data and visualize into a particular visualization. This study analyzed the data collected by using descriptive analysis to interpret the frequency (f) and percentage (percent) in order to obtain the analysis of the objective (Edward, 2019).

\section{Result}

This study has been performed with students from one of the selecteduniversity in north Malaysia to obtain the data needed for this study such as socio demographic information and participants' knowledge and opinion about e-cigarettes.

Table 1 shows that the age of the participants was 22-25 years (55.20 percent), whereby 30.33 percent were males and 25.33 percent were female. The level of education of the respondents consists of bachelor's degree (81.56 percent), with 38 percent are female and 43.33 percent are male followed by foundation with 10.20 percent. The lowest percentage consist of postgraduate students ( 8.22 percent) participating in this research.

Table 1. Demographic information

\begin{tabular}{lccc}
\hline Characteristic & Frequency & $\begin{array}{c}\text { Percentage } \\
(\boldsymbol{\%})\end{array}$ \\
\hline Gender & Male & 169 & 55.59 \\
& Female & 135 & 44.41 \\
\hline
\end{tabular}




\begin{tabular}{lccc}
\hline Age Group & $18-21$ & 111 & 36.51 \\
& $22-25$ & 168 & 55.20 \\
& $26-28$ & 11 & 3.62 \\
& $>29$ & 14 & 4.61 \\
\hline Level of & Foundation & 31 & 10.20 \\
education & Bachelor's degree & 248 & 81.56 \\
& Postgraduates & 25 & 8.22 \\
\hline
\end{tabular}

Table 2 discusses on e-cigarettes awareness among participants that analyse the level of self-knowledge. In this section, the respondents were asked whether they were aware about e-cigarettes. The survey indicates that 90.64 percent of the respondents reported that they had heard about e-cigarettes, and only 9.54 percent of respondents had never heard about e-cigarettes. The respondents were also asked if they had used e-cigarettes. According to Table 2, almost 63.16 percent of respondents said they had never used e-cigarettes while another 36.84 percent had used e-cigarettes daily.

Respondents were also asked about when the last day they used e-cigarettes. The findings indicate that 63.16 percent of respondents answered that they have never used e-cigarettes. Furthermore, 26.97 percent report that the last time they used e-cigarettes was today (the date they answered this question). Next, 7.24 percent answered they used yesterday and another 2.63 percent used last month.

Next, the question asked where the respondents found information about e-cigarettes. The findings indicate that 11.18 percent of the respondents reported that they know from advertisements. While only 2.30 percent of the respondents answered that they know from their own family. Besides, most of the respondents in this survey obtained information from their friend which is 50.99 percent followed by from the internet 29.93 percent. Respondents also stated that they obtained information from television 5.60 percent.

Viewpoints of respondents on the subject matter were also questioned. The questions include the perceived thought of respondents whether e-cigarettes are less harmful than normal cigarettes. This study reported that 50.66 percent agreed that e-cigarettes are less harmful. However, another 49.54 percent appears to contradict with this point. In addition, the respondents were also asked if they thought that e-cigarettes help people to quit smoking. The findings indicate that 50.66 percent of the respondents disagreed on this statement while only 49.34 percent believed that e-cigarettes can help people to stop smoking.

The study also questioned respondents' view about e-cigarettes to their health. The findings of the survey indicate that 17.43 percent believe that e-cigarettes cause minor health effects. Furthermore, 28.95 percent of respondents also believe that e-cigarettes will give a moderate health effect. Next, 43.42 percent of the respondents mention that e-cigarettes will give a serious health effect while another 10.20 percent believe that there is no side effect.

Furthermore, the awareness question was also asked to the respondents which analyse the level of awareness of e-cigarettes. For example, the respondents were not aware of the danger of smoking e-cigarettes, which is similar to normal cigarettes. Majority of the respondents 69.08 percent believe the danger of e-cigarettes is the same as normal cigarettes. However, few respondents 30.92 percent still lack knowledge about the risk of ecigarettes.

The respondents were also asked if they feel more irritated because they could not smoke in a day. The findings of the study posits that 18.09 percent of the respondents reported that they felt very irritable when they could not smoke while 18.75 percent of the respondents did not feel anything. However, most of the respondents were not a smoker, which is 63.16 percent. In addition, the question 'Do you feel nervous, restless, or anxious because you could not smoke in a day' was asked to the respondents. The findings show that 13.48 percent of the respondents felt nervous, restless and anxious followed by 23.36 percent did not have any symptoms, and also 63.16 percent of the respondents were also not smokers.

Meanwhile, 7.53 percent answered that the institution provides hand-outs about the danger of e-cigarettes. Next, 20.39 percent of the respondents answered that the information were discussed in class followed by 8.22 percent said they get help from a nurse or counsellor, and 12.17 percent mentioned that they obtain information from programs in university to help e-cigarettes users. However, 51.64 percent answered that information on the danger of e-cigarettes has never been discussed in the university. 
Table 2. Awareness of Electronic Cigarettes

\begin{tabular}{|c|c|c|c|}
\hline & Characteristic & Frequency & Percentage $(\%)$ \\
\hline \multirow{2}{*}{$\begin{array}{l}\text { Have you ever } \\
\text { heard of e- } \\
\text { cigarettes? }\end{array}$} & Yes & 275 & 90.46 \\
\hline & No & 29 & 9.54 \\
\hline \multirow{2}{*}{$\begin{array}{c}\text { Have you ever used } \\
\text { an e-cigarette? }\end{array}$} & Yes & 112 & 36.84 \\
\hline & No & 192 & 63.16 \\
\hline \multirow{4}{*}{$\begin{array}{l}\text { When was the last } \\
\text { time you used an e- } \\
\text { cigarette? }\end{array}$} & Today & 82 & 26.97 \\
\hline & Last day & 8 & 2.63 \\
\hline & Last month & 22 & 7.24 \\
\hline & Have never used an e-cigarette & 192 & 63.16 \\
\hline \multirow{5}{*}{$\begin{array}{l}\text { Where mostly did } \\
\text { you find out the } \\
\text { information about e- } \\
\text { cigarettes? }\end{array}$} & Advertisement & 34 & 11.18 \\
\hline & Family & 7 & 2.30 \\
\hline & Friends & 155 & 50.99 \\
\hline & Internet & 91 & 29.93 \\
\hline & Television & 17 & 5.60 \\
\hline \multirow{2}{*}{$\begin{array}{l}\text { Do you think e- } \\
\text { cigarettes are less } \\
\text { harmful than } \\
\text { tobacco cigarettes? }\end{array}$} & Yes & 154 & 50.66 \\
\hline & No & 150 & 49.54 \\
\hline \multirow{2}{*}{$\begin{array}{l}\text { Do you think that e- } \\
\text { cigarettes help } \\
\text { people to quit } \\
\text { smoking? }\end{array}$} & Yes & 150 & 49.34 \\
\hline & No & 154 & 50.66 \\
\hline \multirow{4}{*}{$\begin{array}{l}\text { What do you feel } \\
\text { about the e- } \\
\text { cigarette? }\end{array}$} & Give a minor health effect & 53 & 17.43 \\
\hline & Give a moderate health effect & 88 & 28.95 \\
\hline & Give a serious health effect & 132 & 43.42 \\
\hline & No effect & 31 & 10.20 \\
\hline \multirow{2}{*}{$\begin{array}{l}\text { Are you aware that } \\
\text { the dangers of } \\
\text { smoking electronic } \\
\text { cigarettes are just } \\
\text { like traditional } \\
\text { cigarette smoking? }\end{array}$} & Yes & 210 & 69.08 \\
\hline & No & 94 & 30.92 \\
\hline \multirow{3}{*}{$\begin{array}{l}\text { Did you feel more } \\
\text { irritable because } \\
\text { you could not smoke } \\
\text { in a day? }\end{array}$} & Yes & 55 & 18.09 \\
\hline & No & 57 & $18 . .75$ \\
\hline & I do not smoke & 192 & 63.16 \\
\hline \multirow{3}{*}{$\begin{array}{c}\text { Did you feel } \\
\text { nervous, restless, or } \\
\text { anxious because you } \\
\text { could not smoke in a } \\
\text { day? }\end{array}$} & Yes & 41 & 13.48 \\
\hline & No & 71 & 23.36 \\
\hline & I do not smoke & 192 & 63.16 \\
\hline \multirow{5}{*}{$\begin{array}{c}\text { Does your } \\
\text { University offer any } \\
\text { information about } \\
\text { the dangers of } \\
\text { smoking? }\end{array}$} & Handouts about e-cigarettes & 23 & 7.53 \\
\hline & Talked about it in class & 62 & 20.39 \\
\hline & $\begin{array}{l}\text { Students who use e-cigarettes } \\
\text { can get help from a nurse or } \\
\text { counsellor }\end{array}$ & 25 & 8.22 \\
\hline & $\begin{array}{c}\text { Program in university to help } \\
\text { e-cigarettes users }\end{array}$ & 37 & 12.17 \\
\hline & $\begin{array}{l}\text { Never discussed the use of e- } \\
\text { cigarettes in university }\end{array}$ & 157 & 51.64 \\
\hline
\end{tabular}




\section{Discussion}

E-cigarettes are deemed as a current trend among adults, especially students. This evaluation was conducted to identify the dominance of students who are most aware of the outcome of the study that is comparable to (Adib et al., 2018), whereby female students are more aware compared to male students. This analysis concentrates on the students' understanding of e-cigarette, which have been tested in a gender-based analysis in this research that performs tests among males and females. Hence, this study found that most of the respondents $(n=304)$ were aware of the impact of e-cigarettes and 124 (40.79 percent) respondents had used the e-cigarette previously.

As the scope of this study focuses on students in university, thus, the majority of respondents are between 22 - 25 years which is 55.20 percent. Meanwhile, only 4.61 percent of the respondents involved in this study are from 29 years and above. This indicates that some parts of the objective are well achieved whereby the study is focused on students. In this study, it was reported that 275 (90.46 percent) of the respondents, know the existence of e-cigarette, a finding that has been proved previously in (Brazier, 2020) when the researcher found that only 124 (40.79 percent) of the respondents have tried to smoke e-cigarette while another 180 (59.21 percent) of the respondents have never tried to smoke.

Therefore, this finding is similar with other studies in (Adib et al., 2018) whereby half of the respondents have never tried to smoke e-cigarettes. This study also reported the awareness of e-cigarettes, which shows that half of the respondents (63.16 percent) have never used e-cigarettes and it was greater among male respondents. This research also has been studied previously in (Anad et al,.2015 ; Khoury et al., 2016). Furthermore, the research clearly shows that most of the respondents know about e-cigarettes from their friends, hence it can be concluded that friends are the biggest influence to the users (see Figure 1).

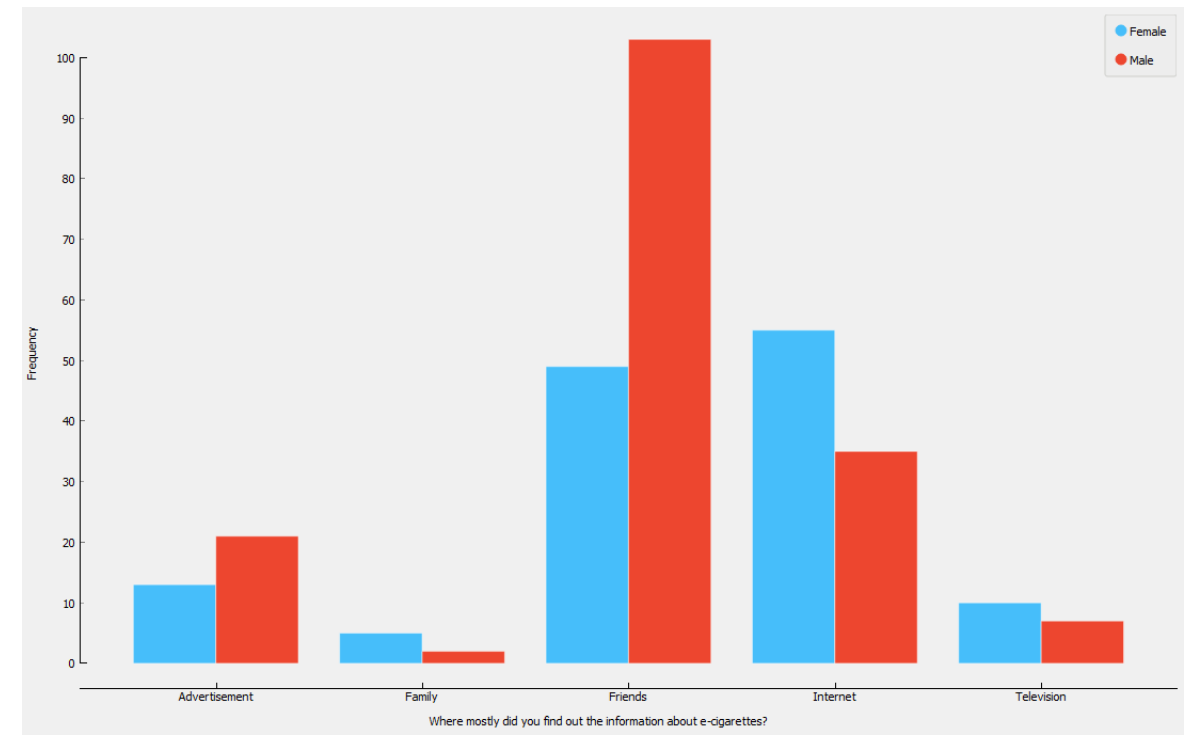

Figure 1. Where mostly did you find out the information about e-cigarettes?

However, differences were obvious on the harmfulness of e-cigarettes. The report shows that 50.66 percent of the respondents believe that e-cigarettes are less harmful than normal cigarettes, and only 49.54 percent of the respondents disagree with this statement. It is similar to a research that has been completed in (Anad et al,. 2015). In addition, this study also reported 43.42 percent of the respondents are clearly aware that e-cigarettes will lead to serious health effects. Meanwhile, 69.08 percent of the respondents also believe that the dangers of e-cigarettes are similar to normal cigarettes. The same observation has also been reported in (Adib et al., 2018) that 68.18 percent of the students realize that the risk of e-cigarette is similar to the typical smoking cigarettes.

Additionally, many students do not realize the risks of e-cigarettes. As a result, some students are still unaware of the dangers of e-cigarettes and have no high awareness of e-cigarettes. Hence, the Health Ministry of Malaysia decided to ban the use of e-cigarettes in university (Jusoh, 2015).Although the study also found that most of the students at 51.64 percent reported that they did not receive any information about e-cigarettes in the university, the results is similar with the study conducted by (Anad et al,. 2015) which stated that e-cigarettes users (89.7 percent) believe that they are not receiving any school information about e-cigarettes. 
There were several limitations related to certain research samples during the study being conducted. First, the study was conducted only in one university, and the scope was quite limited. Therefore, there are limits in terms of data accuracy and misleading data as well as being used in data collection that may lead to a bias in response. Furthermore, the time constraint to complete this study also affects the study due the factor of COVID-19 pandemic, whereby the survey was conducted within a few weeks. In addition, the interview session was rearranged into another option such as online survey to collect the data.

\section{Conclusion}

The need for e-cigarettes can be seen as a rising phenomenon among the younger generation particularly in Malaysia (Adib et al., 2018). The objectives of this study are to identify the awareness of using e-cigarettes among students in university. Hence, there has been a significant result in Table 2, whereby 69.08 percent of the respondents are well aware that the use of e-cigarettes, which give a bad impact to health. In addition, this research study was successfully achieved with 43.32 percent of the respondents agreeing that e-cigarettes are able to cause serious health problems toward smokers. Furthermore, the effect of e-cigarettes needs to be highlighted as lack of knowledge would have a huge impact on adults on trying e-cigarettes because they are easily influenced by their friends. Importantly, attention needs to be paid on the use of this e-cigarette before this trend increases. Besides that, government law enforcement must be restructured to monitor this e-cigarette product from direct to adult access. Institutions are advised to play a constructive role in exposing students to the awareness of e-cigarettes by increasing awareness programs. Overall, this study suggests further research on this area to be conducted in a large scope of population and demographic in Malaysia.

\section{References}

1. Adib, A., Normala, R., Lukman, Z. M., Azlini, C., \& Kamal, M. Y. (2018) Student Awareness about the Use of Electronic Cigarettes in Malaysia. Age, 19(20), 21.

2. Alanazi, A.M. (2016). The Prevalence of Use, Awareness, and Beliefs of Electronic Cigarettes among College-Based Health Care Students at a Southeastern Urban University

3. Anand, V., McGinty, K. L., O'Brien, K., Guenthner, G., Hahn, E., \& Martin, C. A. (2015). E-cigarette use and beliefs among urban public high school students in North Carolina. Journal of Adolescent Health, 57(1), 46-51

4. Brazier, Y. (2020). E-cigarettes: How they work, risks, and research. From https://www.medicalnewstoday.com/articles/216550

5. Cheah, Y. K. (2019). Sociodemographic differences in awareness of e-cigarette in Malaysia. Journal of Oncological Sciences, 1.

6. Chezhian, C., Murthy, S., Prasad, S., Kasav, J. B., Mohan, S. K., Sharma, S., Singh, A. K., \& Joshi, A. (2015). Exploring Factors that Influence Smoking Initiation and Cessation among Current Smokers. Journal of clinical and diagnostic research: JCDR, 9(5), LC08-LC12. https://doi.org/10.7860/JCDR/2015/12047.5917

7. Daniluk, A. (2020). Electronic Cigarettes and Awareness of Their Health Effects. SpringerLink. https://link.springer.com/chapter/10.1007/5584_2017_83

8. Dresden, D. (2019). How does smoking affect the body? Https:/Www.Medicalnewstoday.Com/Articles/324644\#secondhand-Smoke

9. Edwards, E. (2019). E-cigarettes linked to lung problems, first long-term study on vaping finds. Retrieved from https:/www.nbcnews.com/health/vaping/e-cigarettes-linked-lung-problems-first-longterm-study-vaping-n1101641

10. Jusoh I. (2015). Vape ban in all public universities. https://www.thestar.com.my/news/nation/2015/11/22/vape-ban-at-public-universities.

11. Khoury, M., Manlhiot, C., Fan, C. P. S., Gibson, D., Stearne, K., Chahal, N., \& McCrindle, B. W. (2016). Reported electronic cigarette use among adolescents in the Niagara region of Ontario. CMAJ, 188(11), 794-800.

12. Lotrean, L.M. (2015). Use of Electronic Cigarettes among Romanian University Students: A Crosssectional Study. BMC.Public Health, 15, 358. Doi: 10.1186/s12889-015-1713-6

13. Sharifa Ezat Wan Puteh, Roslina Abdul Manap, Tidi Maharani Hassan, Izzah Syazwani Ahmad, Idayu Badilla IdrisFariza Md Sham, Andrea Ban Yu Lin, Chun Ian Soo, Rashidi Mohamed Pakri Mohamed, Ahmad Irdha Mokhtar, Hazli Zakaria, Jing Lee, Amer Siddiq Amer Nordin, Suthahar Ariaratnam, Mohd Zaliman Mohd Yusoff (2018). The use of e-cigarettes among university students in Malaysia. Tobacco Induced Diseases, 1-11. 
14. Tomashefski, A. (2016). The perceived effects of electronic cigarettes on health by adult users: A state of the science systematic literature review. Journal of the American Association of Nurse Practitioners, 28(9), 510-515.

15. Wong LP, Mohamad Shakir SM, Alias H, Aghamohammadi N, Hoe VC (2016). Reasons for using electronic cigarettes and intentions to quit among electronic cigarette users in Malaysia. J Community Health. 2016; 41:1101-1109. Doi: 10.1007/s10900-016-0196-4

16. World Health Organization (2018). Tobacco Fact Sheet; http://www.who.int/en/news-room/factsheets/detail/tobacco. 